\title{
Behaviour of Boundary Lubricating Additives on DLC Coatings
}

\author{
Ksenija Topolovec-Miklozic*, Frances Lockwood** and Hugh Spikes* \\ * Imperial College London, UK \\ ** Ashland, Inc., Lexington KY, USA
}

\begin{abstract}
The friction properties of a range of boundary lubricating additives in DLC-DLC rolling-sliding contact have been investigated. Two types of commercial DLC have been studied, one hydrogenated diamond-like and the other Cr-doped, nonhydrogenated and graphitic.

The graphitic-type DLC coating initially gave very low boundary friction with additive-free base oil but after a few minutes of rubbing in thin film conditions friction rose to a higher value, similar to that produced immediately by the diamondlike carbon. Some organic friction modifiers were able to preserve this low boundary friction behaviour of the graphitic-type DLC for a full two hour rubbing test. One organic friction modifier, glyceryl monooleate produced a considerable reduction in friction with both types of DLC coating in intermediate speed, though notin very slow speed conditions.
\end{abstract}

The additive molybdenum dithiocarbamate formed a low friction film on both DLC surfaces, with lower friction on the graphitic than on diamond-like carbon one. AFM measurements showed that this was due to the formation of regions of low lateral force on asperities within the rubbed track. ZDDP provided some reduction in friction on both DLC surfaces after rubbing but did not form thick ZDDP tribofilms like those generated on steel surfaces.

\section{KEYWORDS}

\section{DLC, AFM, Friction, Friction modifier additives}

\section{INTRODUCTION}

Diamond-like carbon (DLC) is becoming quite widely used as surface coatings for machine components in lubricated systems such as crankcase engines. One issue of practical concern is the way that these coatings interact with the various additives 
present in formulated lubricants and especially the impact of additive-DLC interactions on friction and wear. This paper describes a study of the influence of various lubricant additives on DLC friction.

In practice DLC coatings are normally used in combination with a non-DLC counterface such as a ferrous alloy. However when testing such combinations it is quite difficult to disentangle the influence of additive-DLC interactions from additivecounterface ones. Since in this study the prime interest was in the interaction of additives with DLC, the influence of lubricant additives on friction in DLC-DLC rolling-sliding contact was investigated.

A number of previous studies have investigated the impact of lubricant additives on DLC lubrication [1]-[9]. Most of these have focused on steel/DLC contacts but a few have looked also at DLC rubbing against DLC. De Barros and coworkers [4] studied the friction and wear behaviour of hydrogenated DLC/DLC systems lubricated by MoDTC and ZDDP-MoDTC solutions in a polyalphaolefin base fluid. Both solutions gave lower friction than the base oil, with the MoDTC-ZDDP additive blend giving lower coefficient of friction than MoDTC alone. XPS analysis of the rubbed surfaces showed the presence of $\mathrm{MoS}_{2}$ and $\mathrm{MoO}_{3}$ for both solutions, but the blend containing ZDDP showed negligible phosphorus on the surfaces.

Haque et al. studied the influence of ZDDP in combination with two types of MoDTC in a reciprocating hydrogenated DLC on cast iron contact [5]. They found that MoDTC-ZDDP reduced friction compared to ZDDP alone and also identified $\mathrm{MoS}_{2}$ and $\mathrm{MoO}_{3}$ on the rubbed DLC surface using XPS. Using AFM they also showed that ZDDP formed very thin ( $c a 2 \mathrm{~nm}$ thick) films, which consisted of short chain zinc pyro- and metaphosphate, on the raised regions of the DLC surface. [6].

In a recent study, Kalin et al. measured the influence of two antiwear additives, an amine phosphate and a ZDDP, on the friction and wear of hydrogenated DLC/DLC. Tests were carried out in reciprocating, sliding contact at temperatures up to $150^{\circ} \mathrm{C}$ [7]. They found that both additives reduced wear at temperatures of $80^{\circ} \mathrm{C}$ and above but that the additives both increased friction. XPS analysis showed the presence of phosphorus and sulphur on the surfaces rubbed with ZDDP at the highest test temperature of $150^{\circ} \mathrm{C}$. The sulphur was in the form of sulphate while the phosphorus appeared to be phosphate. The authors also noted that with base oil alone, friction was considerably lower at $150^{\circ} \mathrm{C}$ than at room temperature and they ascribed this to some graphitization of the DLC surface at high temperature. This was supported by surface analysis using Raman spectroscopy.

Recently it has been found that solutions of a particular additive, glycerol monooleate can give very low friction in DLC-steel lubricated contact when the DLC is nonhydrogenated diamond-like (ta-C), while not doing so for hydrogenated DLC (a-C:H) 
[8]. Further work has indicated that glycerol itself also gives this very low friction behaviour [9], suggesting the existence of a specific polyol-DLC interaction.

\section{TEST METHODS AND MATERIALS}

In this study, friction tests were carried out using a minitraction machine (MTM) operating in mixed rolling-sliding conditions. In these tests, a DLC-coated steel ball was loaded and rubbed for two hours against a DLC-coated steel disc immersed in lubricant under thin film lubrication conditions. (Applied load $=31 \mathrm{~N}$, entrainment speed $=0.1 \mathrm{~m} / \mathrm{s}$, slide-roll ratio 0.5 , temperature $=100^{\circ} \mathrm{C}$ ). Periodically during each test, motion was halted and a friction curve obtained. In this, friction was monitored while varying the entrainment speed (mean rolling speed) at fixed slide-roll ratio. (The slide-roll ratio is defined as the ratio of sliding speed to mean rolling speed). .

MTM steel balls (root mean square roughness $=11 \mathrm{~nm}$ ) and discs (root mean square roughness $=11 \mathrm{~nm}$ ) were coated with diamond like carbon coating (DLC) by Teer Coatings Ltd, UK. Two types of DLC were applied, one amorphous, primarily sp3 and hydrogenated, denoted $d-D L C$ in this paper, and the other primarily sp2 and nonhydrogenated, denoted $g-D L C$. The d-DLC coating consisted of a transition layer consisting of $0.6 \mu \mathrm{m}$ of $\mathrm{Cr}$ and $0.5 \mu \mathrm{m}$ of chromium carbide, on top of which was 0.8 $\mu \mathrm{m}$ of the a-C:H DLC. The g-DLC consisted of $0.2 \mu \mathrm{m}$ of Cr with chromium carbide and carbon-rich, non-hydrogenated top layers on top of this, with a combined thickness of $1.6 \mu \mathrm{m}$. The uppermost layer was doped with about $2 \% \mathrm{Cr}$ and this may technically be described as a-C:Me. Further details of the preparation of the d-DLC coating, which had commercial name Dymon-iC, can be found in [5][10] while that of the g-DLC, having commercial name Graphit-iC, is given in [11].

At the end of each two hour test, the rubbed track on the MTM disc was examined using contact mode atomic and lateral force microscopy (AFM/LFM). Each rubbed disc was lightly wiped with propanol prior to being analyzed using a Veeco Explorer AFM in contact mode.

Figure 1 shows AFM topography and LFM images of the two DLC coatings on unrubbed MTM discs. The d-DLC surface consists of tightly packed, rounded pads of diameter ca $200 \mathrm{~nm}$. The root mean square roughness of the surface is $12 \mathrm{~nm}$, measured over an area of $5 \mu \mathrm{m} \times 5 \mu \mathrm{m}$. The g-DLC coating surface consists of less closely-packed, pyramidal pads of diameter ca $200 \mathrm{~nm}$ interspersed among smaller pads. The tips of the pads have relatively low lateral force, as indicated by the dark regions in Fig. 1b. The root mean square roughness of g-DLC is $10 \mathrm{~nm}$ measured over an area of $5 \mu \mathrm{m} \times 5 \mu \mathrm{m}$. 
The additives used in this study are listed in Table 1 and these were tested in simple solution in an API group II base oil having viscosity of $5.44 \mathrm{cSt}$ at the test temperature of $100^{\circ} \mathrm{C}$. All were commercial lubricant additives except for octadecylamine which was purchased from Fluka (Sigma-Aldrich) and was used as supplied.

Table 1. Boundary lubricant additives tested

\begin{tabular}{|l|l|l|}
\hline Abbrev. & Description & Conc. wt. \% \\
\hline ZDDP & secondary ZDDP & $0.08 \% \mathrm{P}$ \\
\hline Amine & octadecylamine & $0.5 \%$ \\
\hline GMO & glycerol monooleate ester & $0.5 \%$ \\
\hline MoDTC & molybdenum dialkyldithiocarbamate & $0.3 \%$ \\
\hline PFA & polycondensed fatty acid / ester & $0.5 \%$ \\
\hline
\end{tabular}

\section{RESULTS WITH BASE OIL}

Fig. 2 shows friction curves from tests in which g-DLC and d-DLC were rubbed in base oil alone. The "immed" curve is taken immediately after the temperature stabilized, before any low speed rolling-sliding phase. d-DLC gives quite high boundary (low speed) friction that falls very slightly with rubbing. This behaviour is rather different from that seen in previous work using similar coatings in dry contact, where the friction of d-DLC fell markedly during rubbing. This was ascribed to graphitisation [10] and it is possible that the presence of base oil in the current study may prevent this process

As seen in Fig. 2b, g-DLC initially gives very low boundary friction but this rises to a value similar to, though slightly below, that for d-DLC after about 5 minutes rubbing. During the first five minutes of rubbing, the friction curves for g-DLC show the interesting feature of having higher friction at intermediate speed than at low speed. This will be discussed later in this paper.

At the end of the two hour tests, AFM topography and lateral force maps were obtained from the rubbed track on the discs as shown in Figs 3 and 4. In these maps, as in all subsequent ones in this paper, the direction of rubbing is from right to the left.

For d-DLC, the surface topography appears to have changed quite markedly. However the lateral force map shows that the original ca $200 \mathrm{~nm}$ diameter pads are still present but that these are partially overlaid by large regions having lower lateral force, which may be deposits from the base oil. The surface is criss-crossed with grooves, which at first sight look like original surface polishing marks but are more 
likely to be scratches in the surface film. An AFM topography trace across the edge of the rubbed track (Fig. 3b) shows that $6 \mathrm{~nm}$ of the d-DLC film has been removed (far less than the thickness of the overall DLC layer). For g-DLC, shown in Fig. 4, the original pad structure appears to have persisted almost unchanged over the two hour test. High spots are characterized by having low lateral force, even though the MTM shows high boundary friction. Negligible wear has occurred.

\section{RESULTS WITH ADDITIVE SOLUTIONS}

\section{1 g-DLC}

Figure 5 shows sets of friction curves for g-DLC lubricated with five different boundary lubricant additive solutions, GMO, Amine, PFA, MoDTC and ZDDP. For comparison, also shown in these plots is the immediate friction curve for base oil. With GMO solution the evolution of boundary friction is quite similar to that with base oil, i.e. rapid loss of the low initial friction during rubbing. The behaviour at intermediate speeds is, however, quite different, with much reduced friction after five minutes rubbing in GMO solution. This is discussed later in the paper.

Amine and PFA both appear to postpone the loss of low boundary friction of g-DLC with rubbing that occurs with base oil, to the extent that the friction remains low at very slow speed even after two hours rubbing.

MoDTC behaves in a quite different way. Initially it gives high boundary friction, i.e. it obviates the initial low friction that g-DLC shows with base oil. Boundary friction then falls progressively with rubbing, as, to a lesser extent, does friction at intermediate speed. This reduction of friction during rubbing has been seen in previous work with MoDTC where it has been ascribed to the formation of low shear strength nanocrystallites of $\mathrm{MoS}_{2}$ on rubbing asperities [12].

Like MoDTC, ZDDP solution gives immediately high boundary friction coefficient although this falls slightly (from 0.10 to 0.08 ) with extended rubbing. There is no fall in friction at intermediate speeds, unlike with GMO, but there is also no increase in friction under these conditions as has been reported for ZDDP with steel surfaces [13].

Figure 6 compares the friction properties of g-DLC with all five additive solutions and with the base oil, both immediately and after two hours rubbing. The initial friction coefficient measurements show clearly how MoDTC and ZDDP cancel the low speed low friction response of g-DLC. The two hour plots show how MoDTC reduces boundary friction during rubbing and also how Amine and PFA maintain the low friction properties of g-DLC at very low speeds. 
Figure 7 shows AFM measurements carried out on the rubbed surfaces after two hour rubbing tests. ZDDP forms a patchy coating with lower lateral force than the surrounding regions. MoDTC forms areas of markedly low lateral force, only on asperity peaks. Topography profiles across the edge of the contact showed that ZDDP exhibited no wear, while for MoDTC there was less than $10 \mathrm{~nm}$ wear.

\section{$4.2 \quad d-D L C$}

Figure 8 compares friction curves for d-DLC rubbed in base oil and three additive solutions. Immediate friction measurements show that ZDDP and MoDTC give a slight reduction in slow speed friction. After two hours rubbing, boundary friction has fallen still further, although, for MoDTC much less than occurred with g-DLC. GMO has no effect on slow speed friction but, as with g-DLC, produces a marked reduction in friction at intermediate speeds.

Figure 9 shows AFM topography and lateral force images from the d-DLC surfaces after two hours rubbing. ZDDP produces surfaces which maintain the original pad structure but show a scratched pattern similar to that produced by rubbing in base oil (Fig. 3a). Rubbing in MoDTC produces a surface that consists of close-packed asperities having diameter ca $150 \mathrm{~nm}$. The tips of these asperities have low lateral force. Again, ZDDP prevents the d-DLC coating from wear very effectively, with no measurable wear, while MoDTC shows less than $8 \mathrm{~nm}$ wear..

\section{DISCUSSION}

In this study, two quite different DLCs have been studied and it is clear that their properties and response to friction modifiers is rather different.

The behaviour of the d-DLC is the more straightforward of the two. The coating itself gives quite high boundary friction coefficient $(0.115)$ in base oil at slow speed and this is almost unaffected by the presence of organic friction modifier, GMO, although, as will be discussed below, mixed friction is quite strongly influenced by this additive. ZDDP reduces boundary friction coefficient almost immediately (to 0.09). Since this occurs even without previous rubbing it would appear to originate from adsorption or the formation of a very thin reaction film rather than a thick phosphate film as occurs with steel. This is supported by AFM maps which show no evidence of large pad growth and from topography traces across the edge of the track which show no increase in height inside the rubbed region (Fig. 10). This is consistent with the observations of Haque et al. [6]. 
MoDTC clearly forms a friction-reducing film on d-DLC, although the slow speed coefficient of friction reduction is relatively modest (to 0.09). This film takes the form of rows of tiny pads, a few nanometers high, each pad showing low lateral force. These low friction regions are characteristic of the friction response of MoDTC and are almost certainly nanocrystallites of $\mathrm{MoS}_{2}$ formed from MoDTC by a tribochemical reaction [12][14]. Such pads are normally found to form only on asperity peaks, where their generation is believed to be stimulated by solid-solid rubbing. Interestingly, these pads are not oriented along the sliding direction as reported previously [15], but follow the topographic morphology features of the coating, which, for the area shown, are oriented perpendicular to the sliding direction. Figure 10 shows these low lateral force regions at higher resolution on both d-DLC and gDLC rubbed surfaces and show clearly how low lateral force is present only on the high spots on the surfaces. The line profile across the edge of the rubbed track in Fig. 11 shows that the MoDTC reaction film is very thin since it does not produce a step at the edge of the track.

The g-DLC is characterized by having initially very low boundary friction when rubbed in base oil. This has been previously reported and presumably represents the lower shear strength of a primarily $\mathrm{sp}^{2}$ carbon material, with a structure having some two dimensional molecular characteristics compared to carbon with primarily $\mathrm{sp}^{3}$ bonding. Interestingly, this low shear strength is lost after about 10 minutes rubbing in base oil, perhaps because the immediate surface having low shear strength is worn away. Tests with organic friction modifier additives show that two of these (octadecylamine and polycondensed fatty acid/ester) prevent the loss due to rubbing of the low friction properties of g-DLC, while another, GMO does not. This may be due to adsorption of the amine and the PFA on the graphitic surface. Long chain amines have been found to form intercalation compounds with graphite oxide [16] while scanning tunneling microscopy has demonstrated the adsorption of fatty acids from hydrocarbon solvent on graphite surfaces [17]. MoDTC and ZDDP both immediately cancel the low friction properties of g-DLC, but both go on to form friction-reducing films during prolonged rubbing. AFM profiles across the edge of the contact show that these films do not significantly raise the height of the surface and, indeed, for MoDTC show the loss of $20 \mathrm{~nm}$ in the rubbed track, presumably due to wear.

In view of the similarity of the ZDDP and MoDTC response on the two surfaces it is unlikely that the presence of chromium in the g-DLC plays a significant role in the additives' responses.

One surprising observation is the influence of GMO on friction in the intermediate speed regime. On both DLC surfaces, GMO very markedly reduces the friction in the entrainment speed range 0.07 to $0.5 \mathrm{~m} / \mathrm{s}$, effectively shifting the friction-speed curve to the left, while not significantly reducing the boundary friction coefficient at very slow speed. This type of behaviour has been reported previously with a variety of 
lubricants [18][19] and been ascribed to the formation of very thin reacted or adsorbed layers on the solid surfaces with higher viscosity than the bulk lubricant. When the speed and thus EHL film thickness is reduced to the thickness of these layers, the latters' viscous nature enables a fluid film to continue to be formed down to lower speed than expected from the bulk lubricant viscosity. An alternative explanation is that the GMO forms an adsorbed film that is able to survive (and reduce friction) on asperities when a high proportion of the load is being supported by a fluid film, i.e. at intermediate speeds. However at very low speeds, when there is no contribution to load support from fluid entrainment, the asperity pressure exceeds the level that the adsorbed GMO (or glycerol) film can withstand.

Previous work has shown that amorphous non-hydrogenated DLC can give very low friction with GMO and glycerol [8][9], which implies a specific glycerol-DLC adsorption. However it is not yet possible to be sure which of the two alternative mechanisms outlined above may be responsible for this.

One final, interesting feature of some of the friction results is that they show higher friction at intermediate speeds than they do at slow speed. This is seen for the g-DLC in initial stages of rubbing and, when Amine and PFA are present, through to the end of the two hours tests. It is also present after two hours rubbing of g-DLC with MoDTC.

This behaviour has been previously reported for organic molybdenum additives [20]. It implies that the films present at lubricated asperity contacts at high sliding speed have higher shear strength than they do at low sliding speed. This might be due to a thermal effect, i.e. as the entrainment speed and thus the sliding speed rises, a frictionreducing boundary film present on the surfaces becomes disordered or breaks down. Flash temperature theory [21][22] indicates a maximum flash temperature rise of $5{ }^{\circ} \mathrm{C}$ at an entrainment speed of $0.1 \mathrm{~m} / \mathrm{s}$ and $16{ }^{\circ} \mathrm{C}$ at $0.5 \mathrm{~m} / \mathrm{s}$. (This assumed a coefficient of friction of 0.11 , the maximum measured, and is based on the steel-steel contact with thermal conductivity $35 \mathrm{~W} / \mathrm{mK}$ and thermal diffusivity $1.0 \times 10^{-5} \mathrm{~m}^{2} / \mathrm{s}$. It neglects the impact of the DLC coating on thermal properties of the rubbing conjunction). An alternative possibility is that very thin, high pressure, hydrocarbon film, just one or two molecules thick, may have higher shear strength that the graphite or $\mathrm{MoS}_{2}$ monolayer interface. Thus, when the surfaces become separated by a very thin oil film the friction actually increases. At still higher speeds, the oil film becomes thicker and consequently weaker under shear.

\section{CONCLUSIONS}

MTM friction and AFM topography and lateral force measurements have been made for DLC rolling-sliding against DLC in solutions of several boundary lubricating 
additives. The behavior of two types of DLC coating, one graphitic-like and one diamond-like has been investigated.

The graphitic-like DLC gives initially low boundary friction coefficient but this rises during rubbing to approach the value for the diamond-like carbon coating. This friction rise can be postponed if appropriate organic friction modifiers are present. ZDDP and MoDTC react to form very thin, friction-reducing films on both DLCs. The similarity of AFM images of the MoDTC films to those produced on steel suggests that they consist of tiny crystallites $\mathrm{MoS}_{2}$, a few nanometers thick.

One organic friction modifier additive, glyceryl monooleate, markedly reduced friction at intermediate speeds on both types of DLC surface. However it gave relatively high friction at low speeds. This may originate from the adsorbed film of this additive or its breakdown products being able to withstand asperity pressures in mixed lubrication but not the higher pressures likely to be present at asperity conjunctions in boundary lubrication conditions.

\section{REFERENCES}

1. Podgornik, B., Jacobson, S., Hogmark, S., 2003, "DLC coating under boundary lubricated conditions - advantages of coating one of the contact surfaces rather than both or none.” Trib. Intern. 36, pp. 843-849.

2. Podgornik, B., Vizintin, J., 2005, "Tribological reactions between oil additives and DLC coatings for automotive applications.” Surf. \& Coat. Techn. 200, pp. 1982-1989

3. Podgornik, B., Hren, D., Vizintin, J., Jacobson, S., Syavlid, N. and Hogmark, S., 2006, "Combination of DLC coatings and EP additives for improved tribological behaviour of boundary lubricated surfaces.” Wear 261, p. 32-40.

4. De Barros, M.I., Bouchet, J., Martin, J.M., Le-Mogne, T. and Vacher B., 2005, "Boundary lubrication mechanisms of carbon coatings by MoDTC and ZDDP additives.” Trib. Intern. 38, pp. 257-264.

5. Haque, T., Morina, A., Neville, A., Kapadia, R. and Arrowsmith, S., "Non-ferrous coating/lubricant interactions in tribological contacts: Assessment of tribofilms." Trib. Intern. 40, pp. 1603-1612, (2007).

6. Haque, T., Morina, A., Neville, A., Kapadia, R. and Arrowsmith, S., "Study of the ZDDP antiwear tribofilm formed on the DLC coating using AFM and XPS.” J. of ASTM Intern. 4, DOI:10.1520/ JAI100937, (2007).

7. Kalin, M., Roman, E. and Vizintin, J., "The effect of temperature on the tribological mechanism and reactivity of hydrogenated amorphous diamond-like carbon coatings under oil lubricated conditons.” Thin Solid Films 515 pp. 36443652, (2007). 
8. Kano, M., 2006, "Super low friction of DLC applied to engine cam follower lubricated with ester-containing oil.” Trib. Intern. 39, pp. 1682-1685.

9. Kano, M., 2006, "DLC coating technology applied to sliding parts of automotive engine.” New Diamond and Frontier Carbon Techn, 16, pp. 201-210.

10. Jarratt, M., Stallard, J., Renevier, N.M. and Teer, D.G., "An improved diamondlike carbon coating with exceptional wear properties.” Diamond and Related Materials 12, pp. 1003-1007, (2003).

11. Teer, D.G., “New solid lubricant coatings.” Wear 251, pp. 1068-1074, (2001).

12. Graham, J., Korcek, S. and Spikes, H.A. "The friction-reducing properties of molybdenum dialkyldithiocarbamate additives. Part 1. Factors influencing friction reduction.” Trib. Trans. 44, pp. 626-636, (2001).

13. Taylor, L. and Spikes, H.A., "Friction-enhancing properties of ZDDP antiwear additive. Part I. Friction and morphology of ZDDP reaction films.” Trib. Trans. 46, pp. 303-309, (2003)

14. Grossiord, C., Varlot, K., Martin, J.M., Le Mogne, Th., Esnouf, C., and Inoue, K., "MoS2 single sheet lubrication by molydenum dithiocarbamate.” Trib. Intern. 31, pp. 737-743, (1998).

15. Topolovec Miklozic, K., Graham, J. and Spikes, H., "Chemical and physical analysis of reaction films formed by molybdenum dialkyldithiocarbamate friction modifier additive using Raman and atomic force microscopy.” Tribology Lett, 11, pp. 71-81, (2001).

16. Matsuo, Y., Watanabe, K., Fulutsuka, T. and Sugie, Y., "Characterization of nhexadecylamine-intercalated graphite oxides and sorbents.” Carbon 41, pp. 15451550, (2003).

17. Hibino, M., Sumi, A., Tsuchiya, H. and Hatta, I., "Microscopic origin of the oddeven effect in monolayer of fatty acids formed on a graphite surface by scanning tuneling microscopy.” J. Phys. Chem. B 102, pp. 4544-4547, (1998).

18. Smeeth, M., Gunsel, S. and Spikes, H.A. "Friction and wear reduction by boundary film-forming viscosity index improvers." SAE Tech. Paper, SAE 962037.

19. Anghel, V. Bovington, C. and Spikes H.A. "Thick film formation by friction modifier additives.” Lubr. Sci. 11, pp.313-335, (1999).

20. Spikes, H.A. and Olver, A.V. "Basics of mixed lubrication.” Lubr. Sci. 16, pp. 328, (2003).

21. Jaeger J C. "Moving surfaces of heat and temperature at sliding contacts." J. Proc. Roy. Soc. New South Wales 76 pp. 203-224, (1942).

22. Greenwood, J A, “An interpolation method for flash temperature.” Wear 150, pp. 153-158, (1991). 


\section{LIST OF FIGURE TITLES}

Fig. 1. AFM and LFM images of the two DLCs studied, (a) d-DLC, (b) g-DLC

Fig. 2. Friction curves for DLC coatings in base oil, (a) d-DLC, (b) g-DLC

Fig.3. AFM measurements for d-DLC after two hours rubbing in base oil (a) topography and lateral force maps, (b) topography profile across edge of rubbing track

Fig.4. AFM measurements for g-DLC after two hours rubbing in base oil (a) topography and lateral force maps, (b) topography profile across edge of rubbing track

Fig.5. Evolution of coefficient of friction for g-DLC with rubbing time in solutions of five additives (a) GMO, (b) PFA, (c) Amine, (d) MoDTC, (e) ZDDP

Fig.6 Comparison of the friction properties of g-DLC with base oil and five additive solutions (a) immediately and (b) after two hours rubbing

Fig.7. AFM topography and lateral force maps from rubbed track on g-DLC disc after two hours rubbing in two boundary lubricating additive solutions; (a) ZDDP, (b) MoDTC

Fig. 8. Comparison of the friction properties of d-DLC with base oil and three additive solutions (a) immediately and (b) after two hours rubbing

Fig. 9. AFM topography and lateral force images for d-DLC after two hours rubbing in two boundary lubricating additive solutions; (a) ZDDP, (b) MoDTC

Fig 10 Topography and LF of d-DLC and g-DLC after two hours rubbing in MoDTC solution

Fig. 11. Profiles across the edge of the rubbed track from two hours rubbing tests for d-DLC in (a) ZDDP and (b) MoDTC solutions 

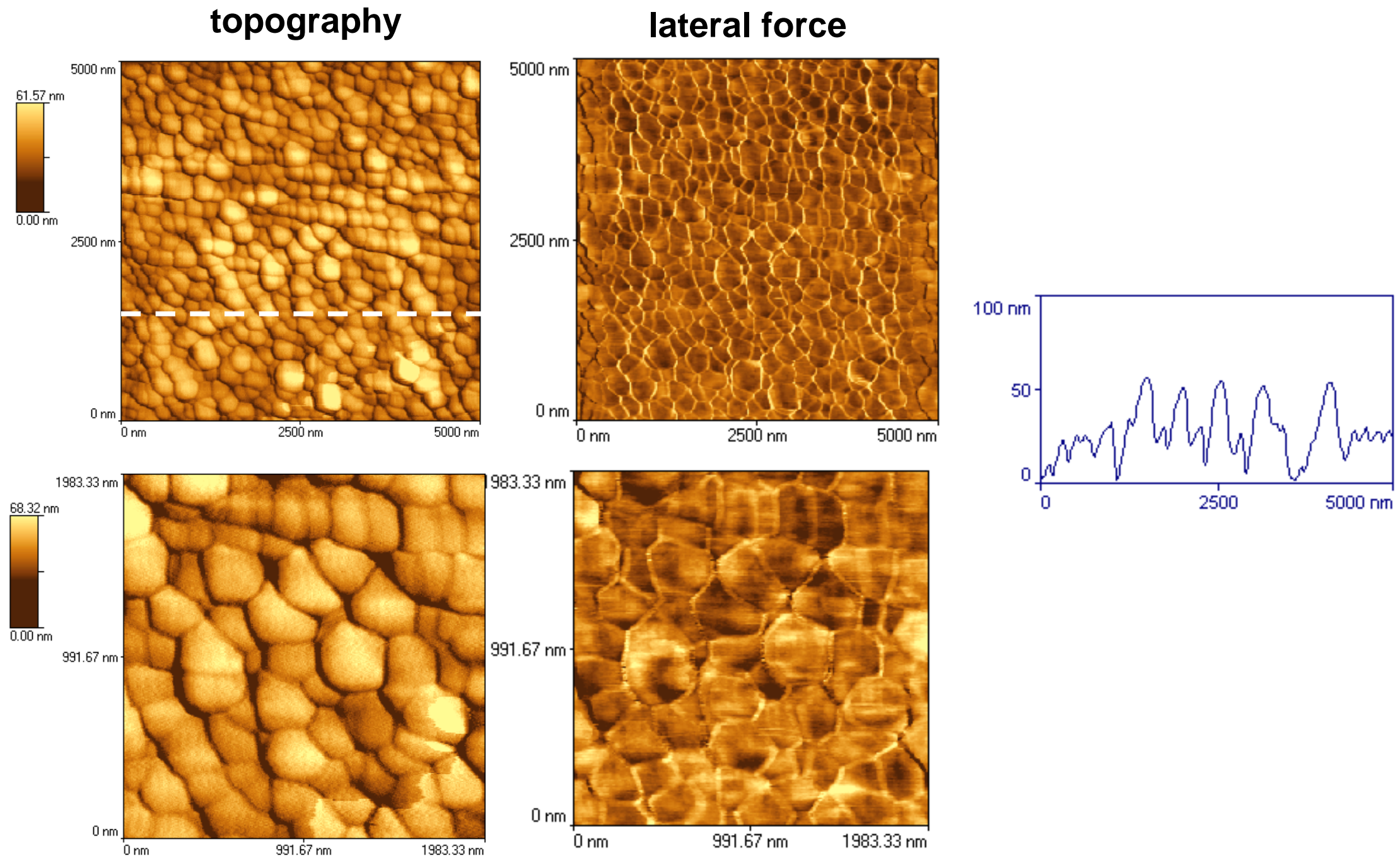

Fig 1a Unrubbed d-DLC coating 

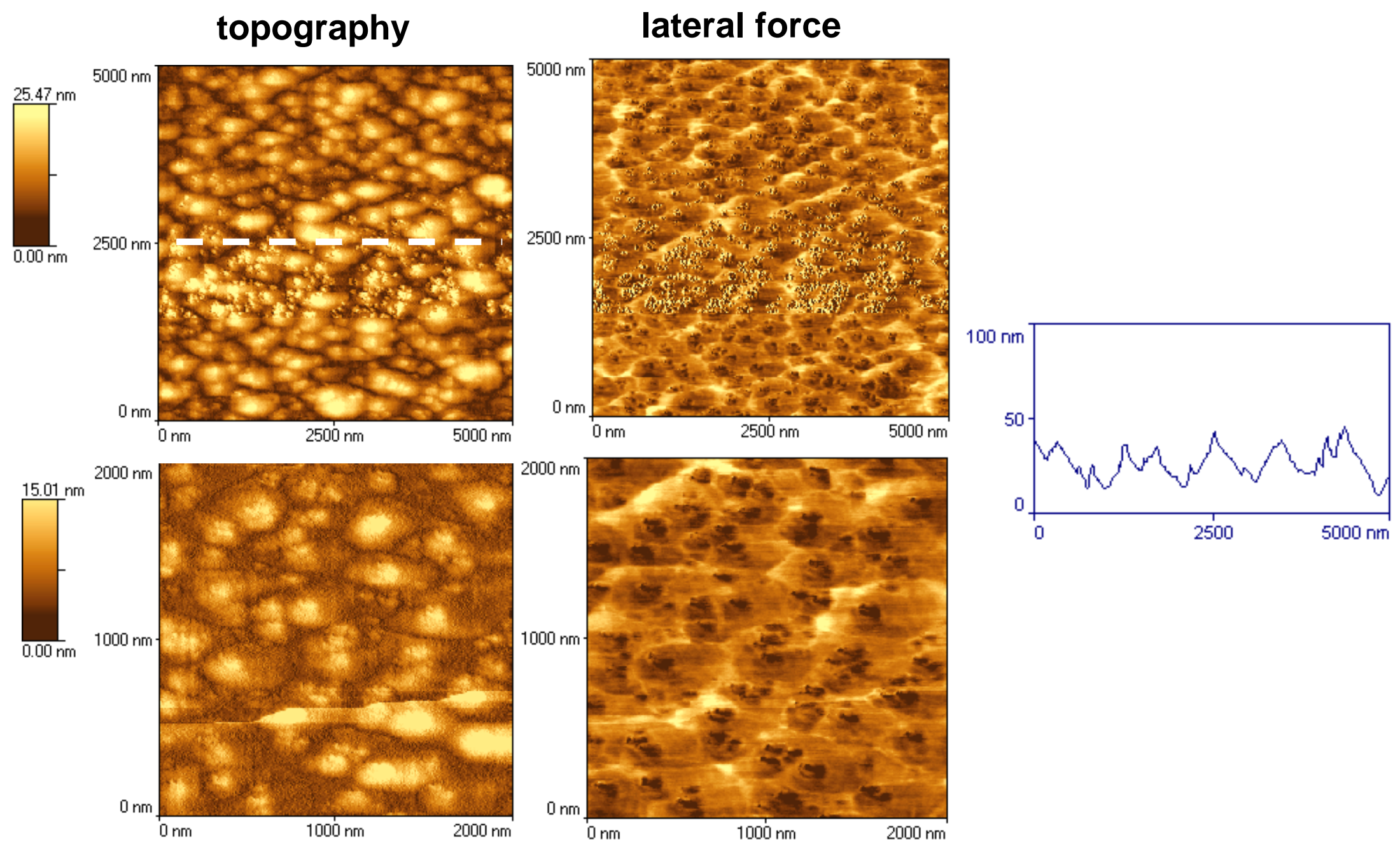

Fig 1b Unrubbed g-DLC coating 


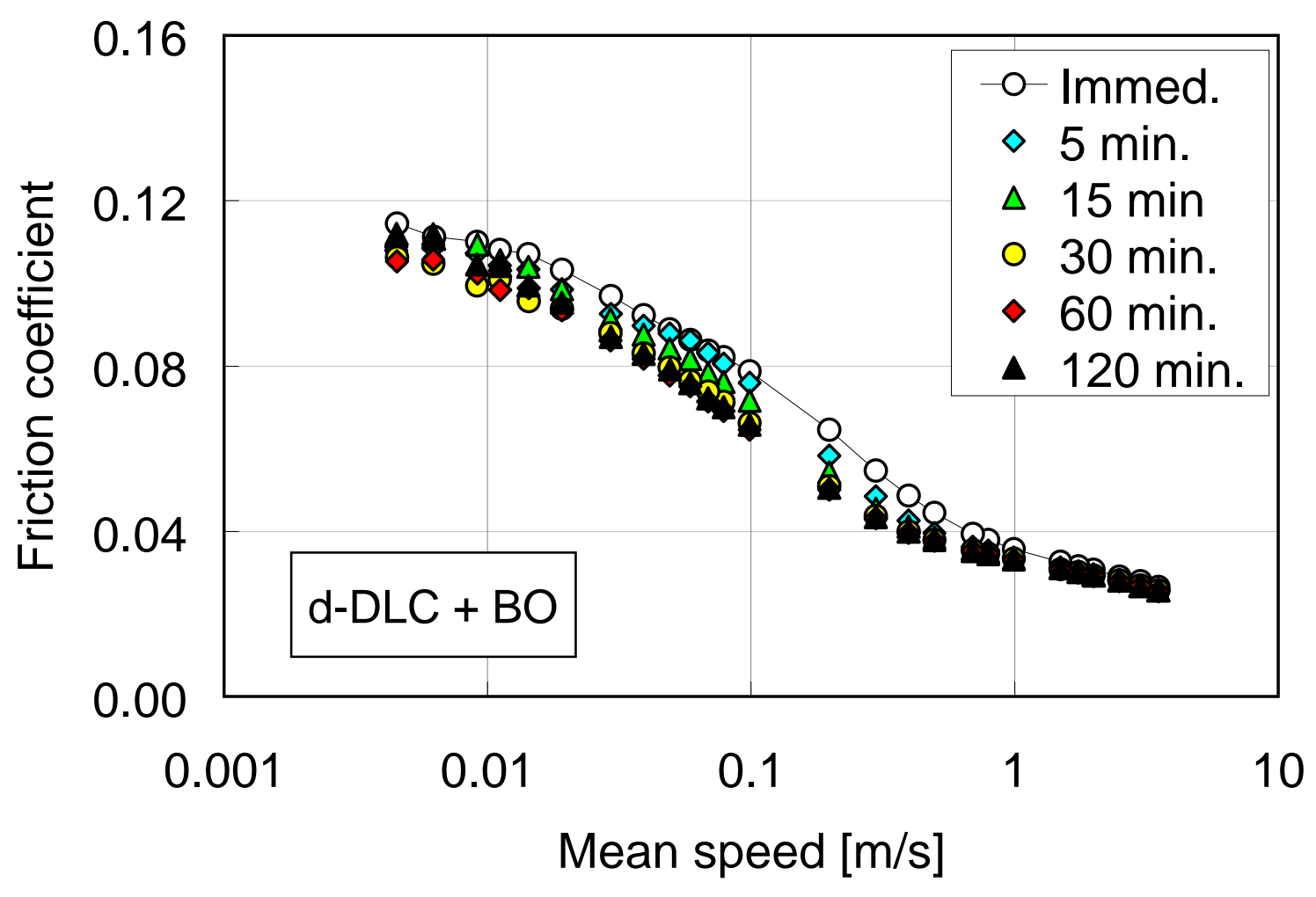

Fig 2a Evolution for friction over rubbing time for d-DLC rubbed in $\mathrm{BO}$ 


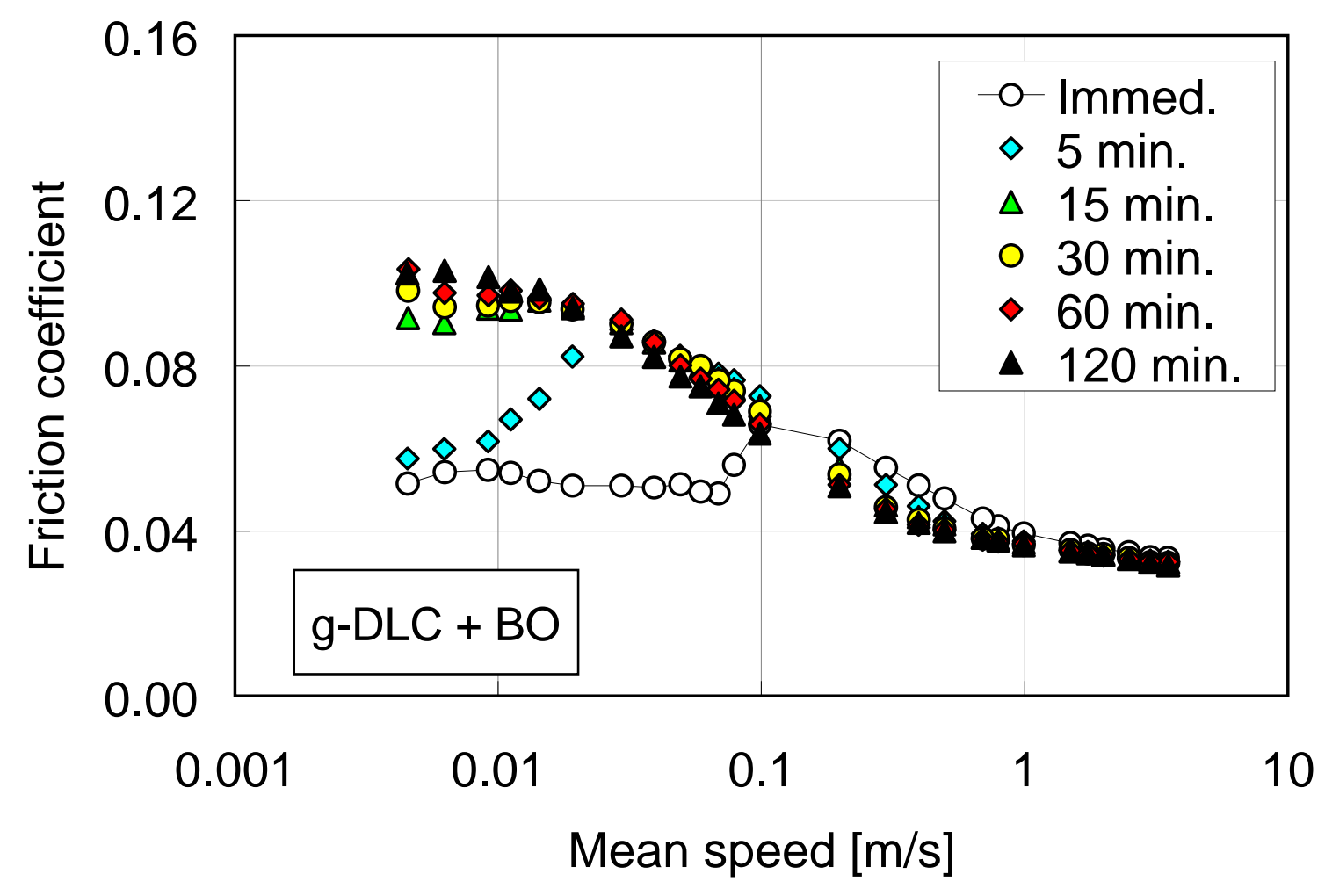

Fig $2 b$ Evolution for friction over rubbing time for g-DLC rubbed in $\mathrm{BO}$ 

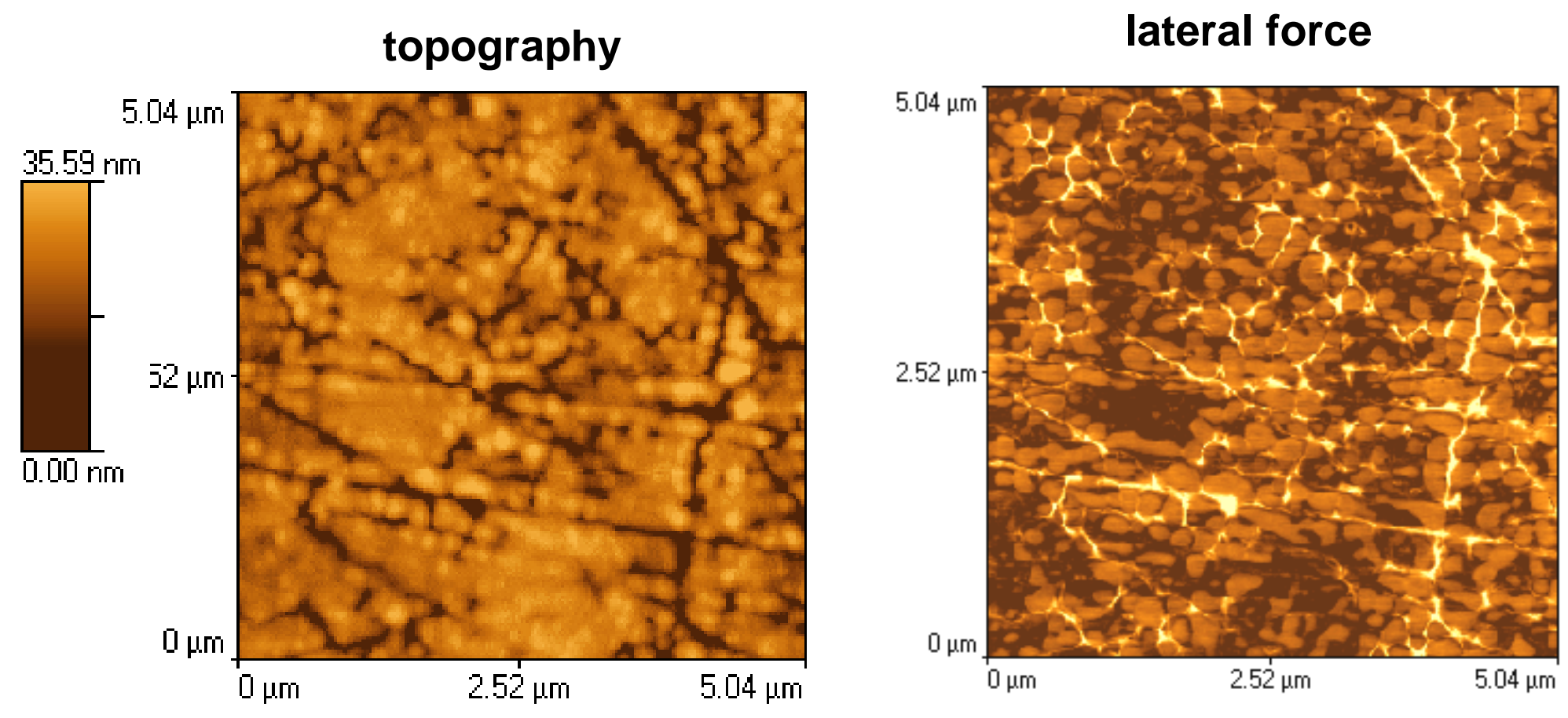

Fig 3a d-DLC after 2 hours rubbing in BO 


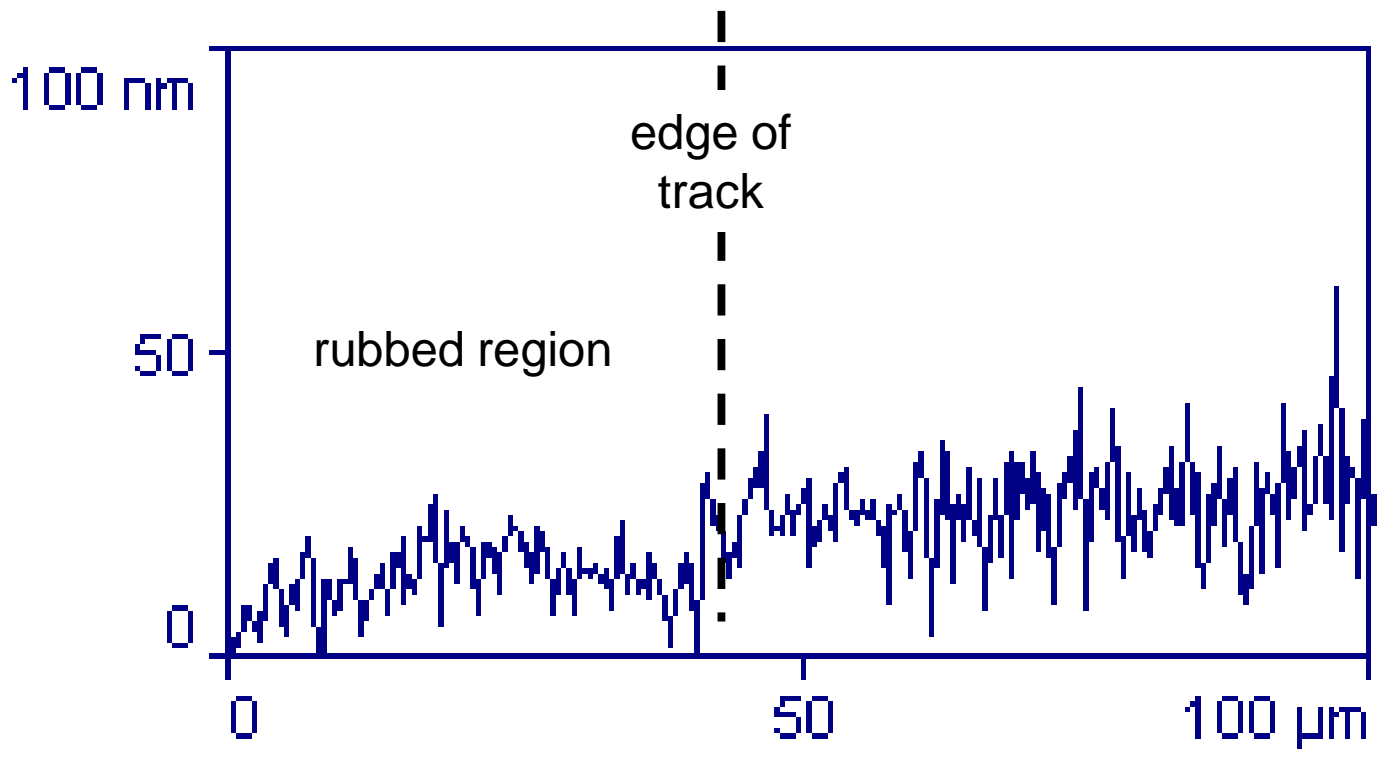

Fig 3b Topography profile across edge of rubbed track for d-DLC 
topography

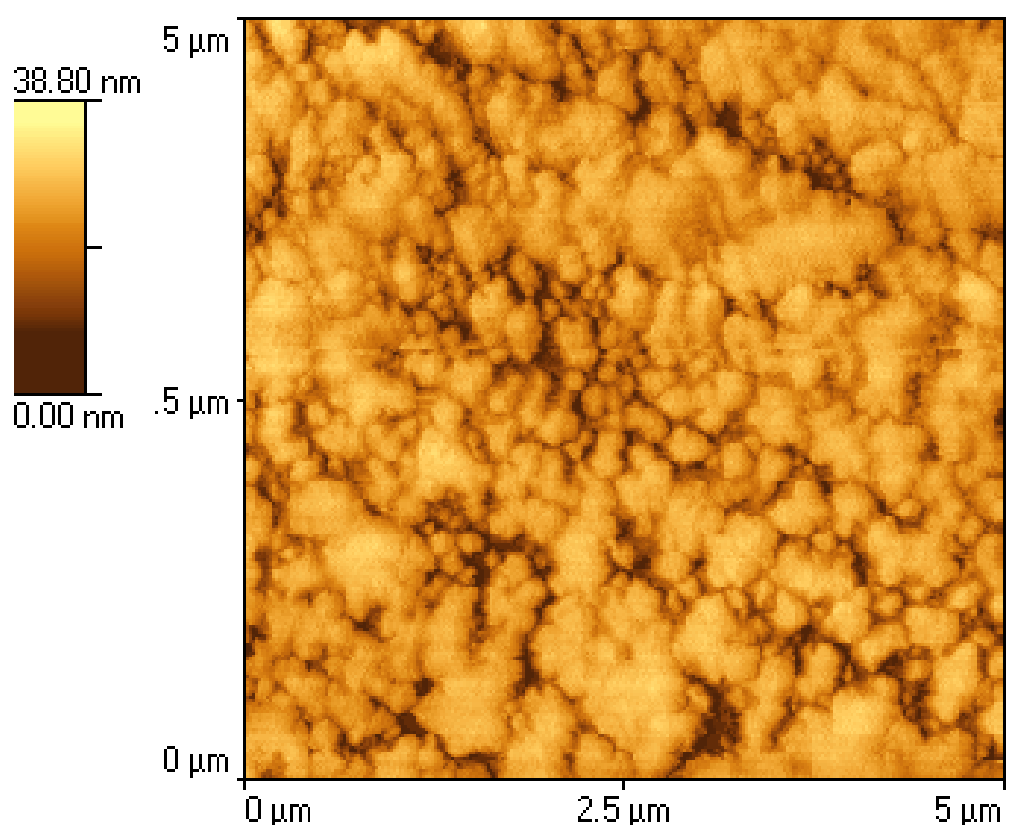

lateral force

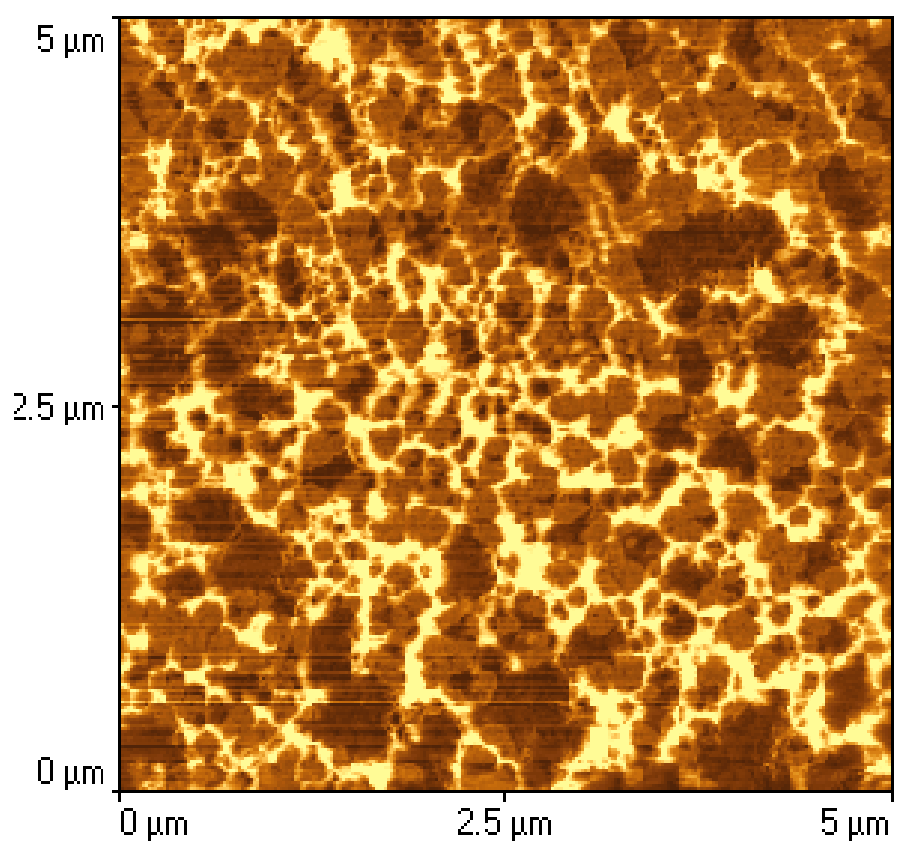

Fig 4a g-DLC after 2 hours rubbing in BO 


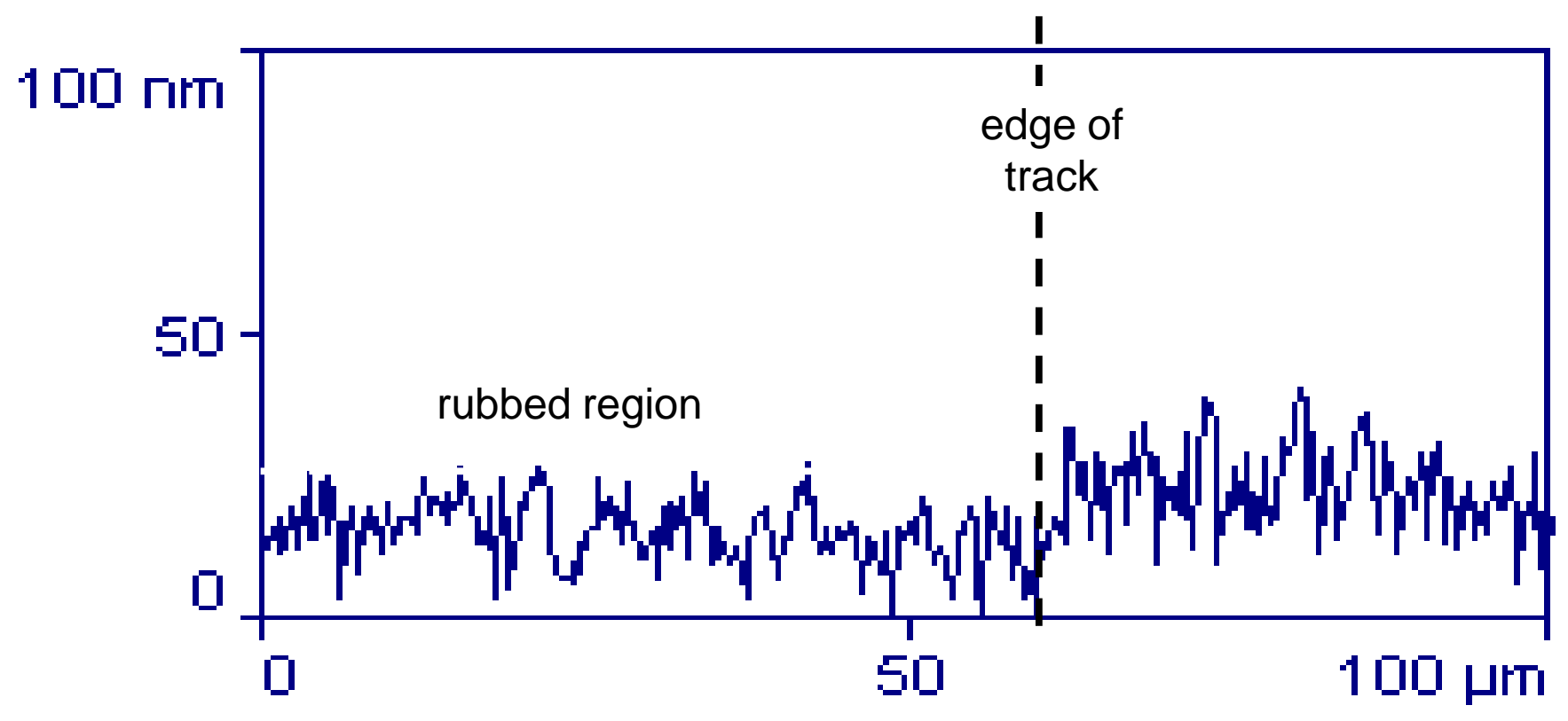

Fig 4b Topography profile across edge of rubbed track for g-DLC 


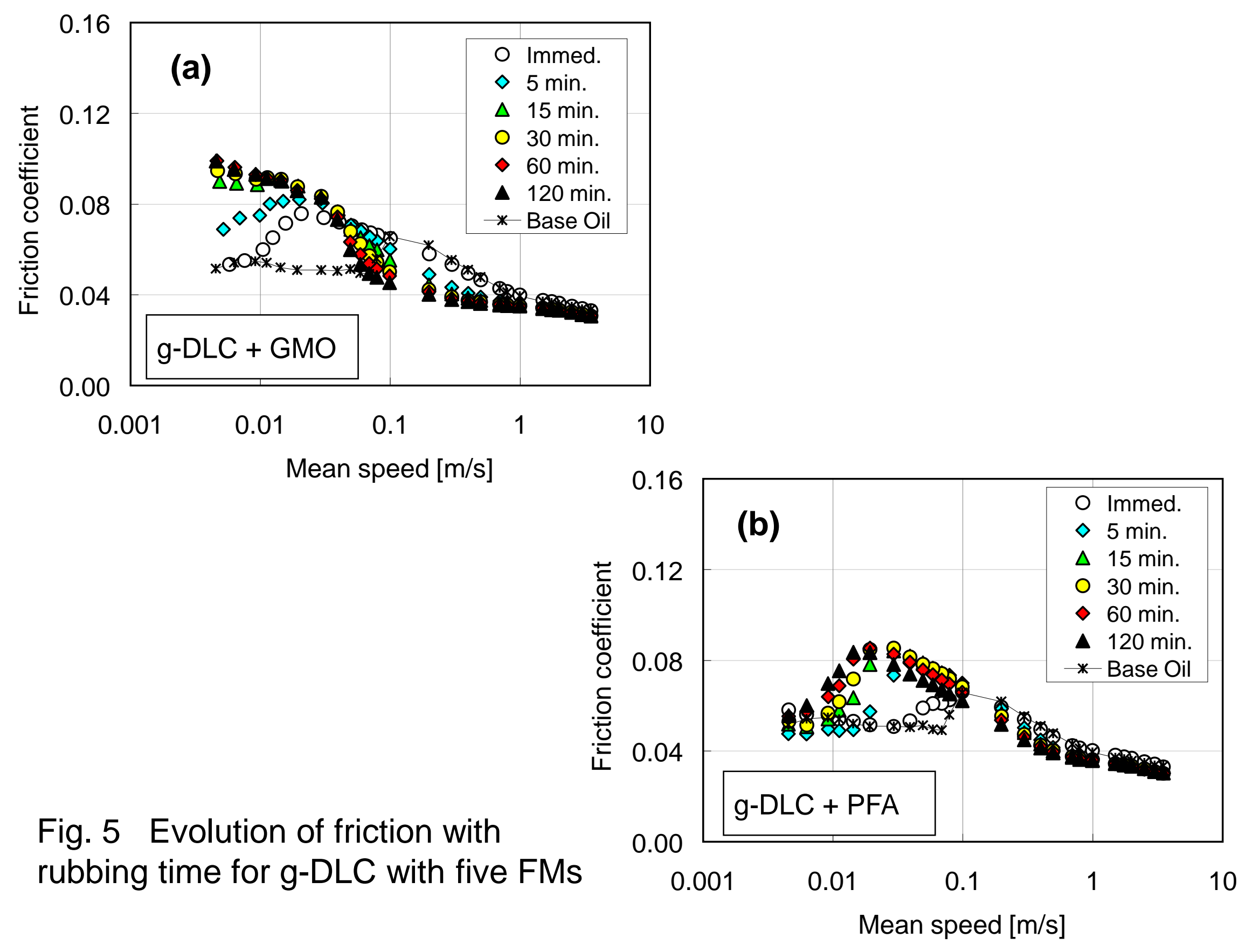




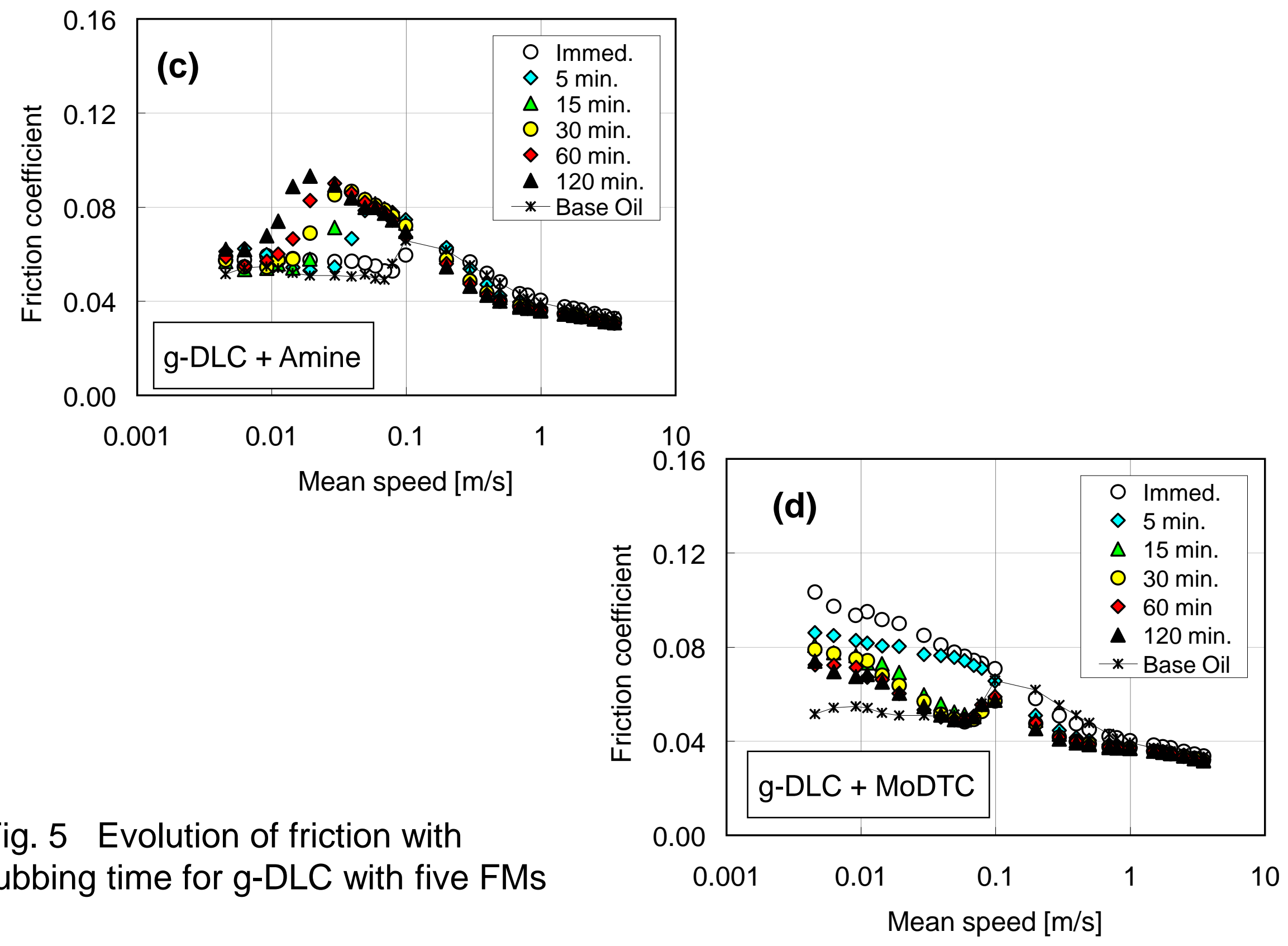




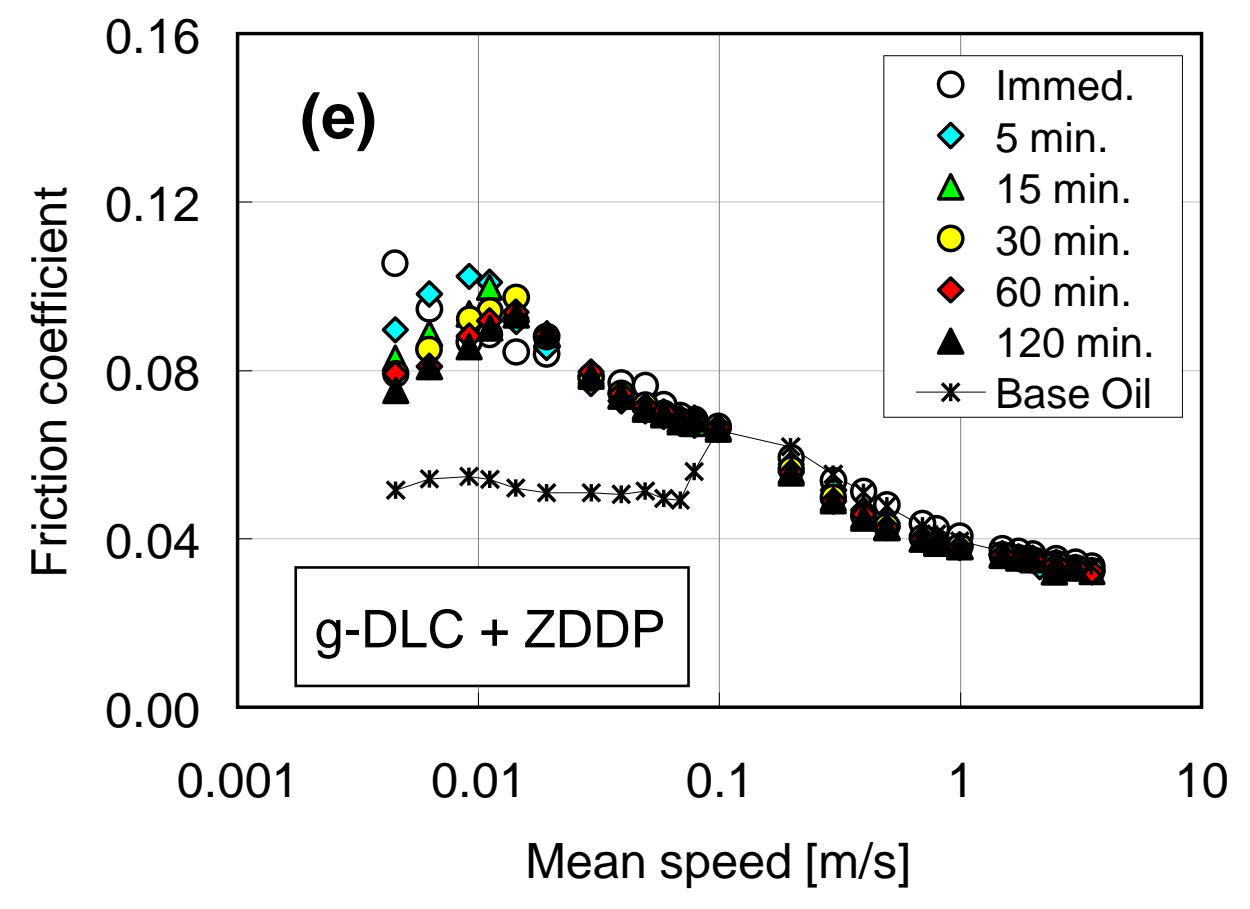

Fig. 5 Evolution of friction with rubbing time for g-DLC with five FMs 


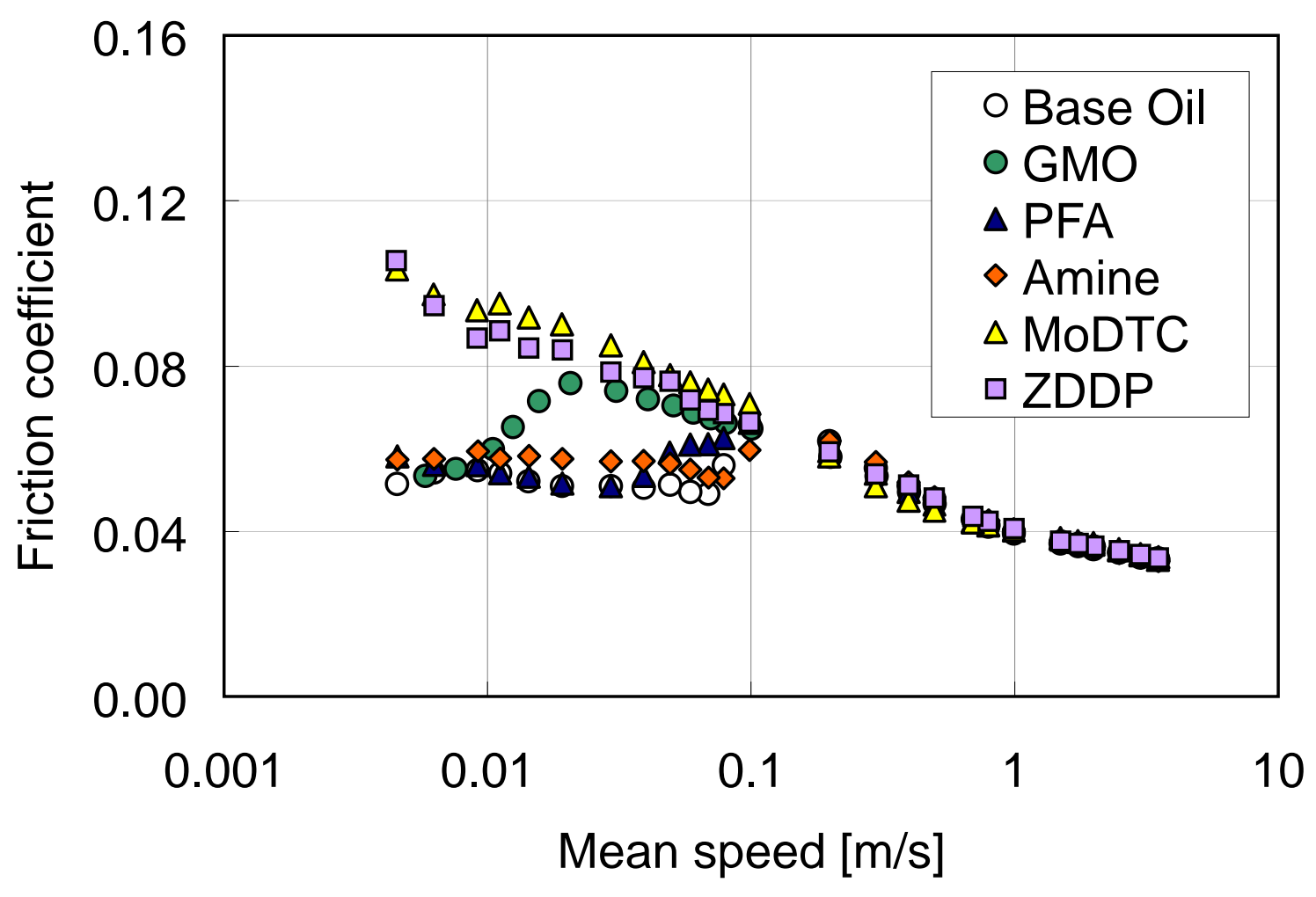

Fig. 6a Immediate effect of FMs on friction for g-DLC 


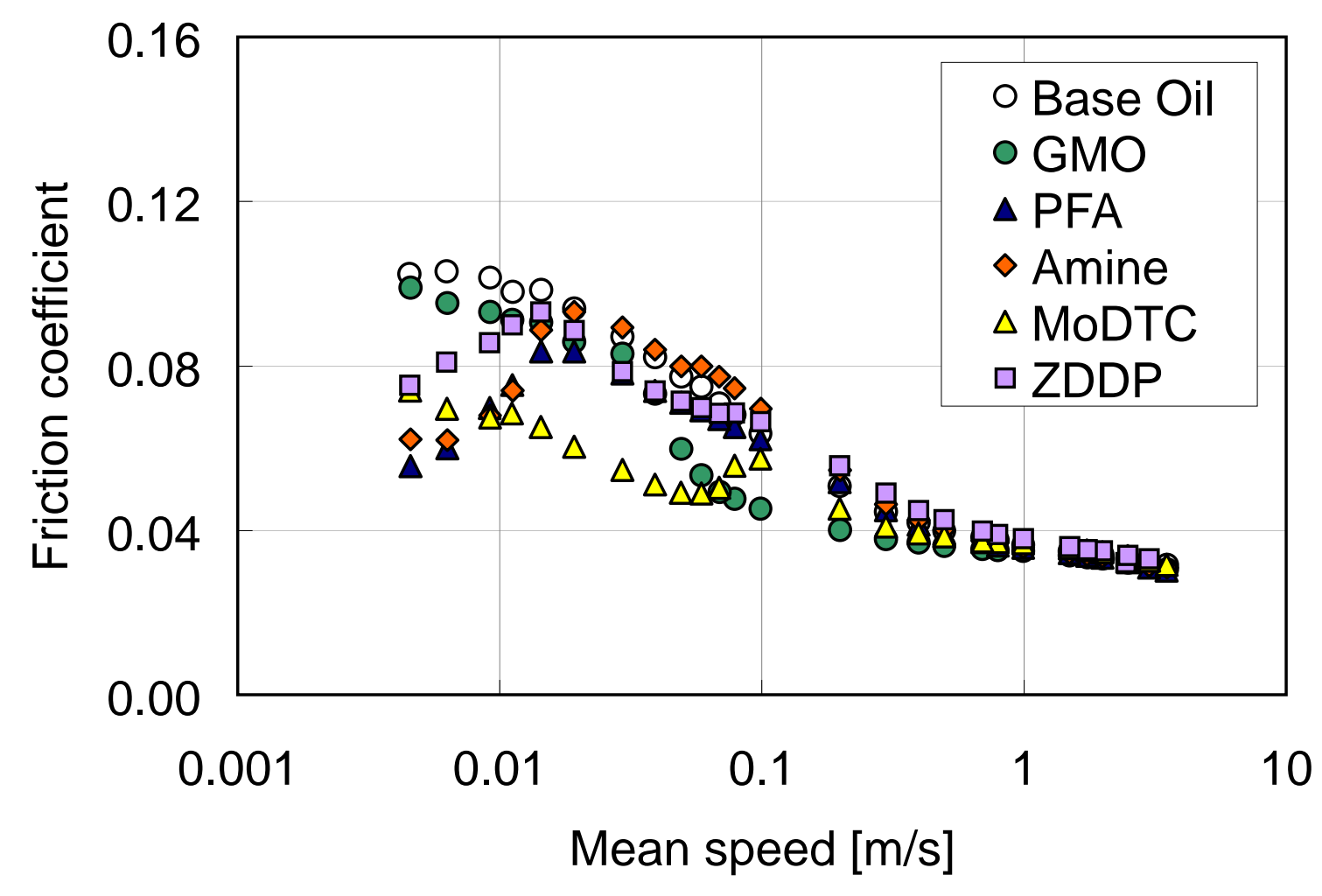

Fig. 6b Effect of FMs on friction after two hours rubbing for g-DLC 
topography
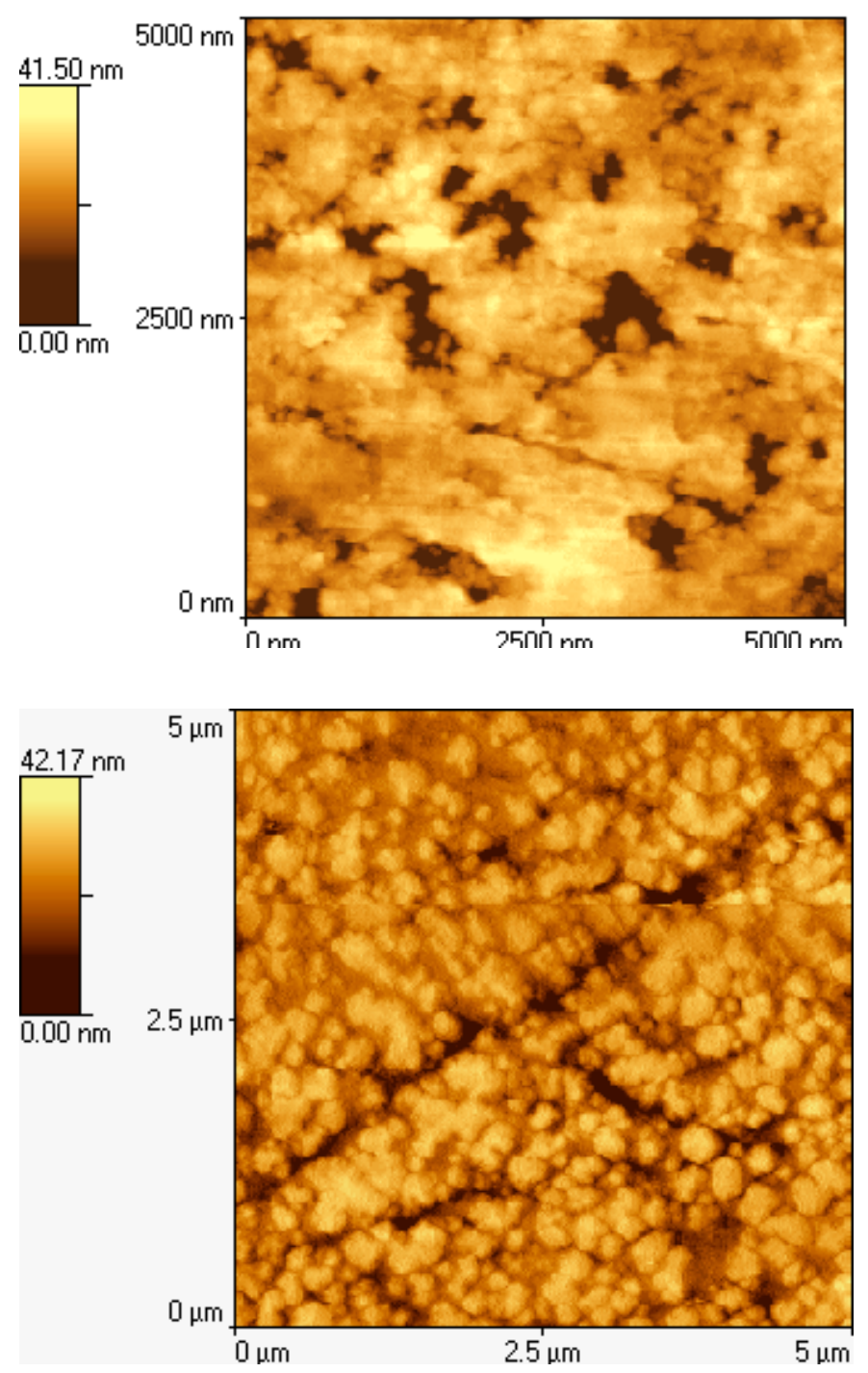

lateral force
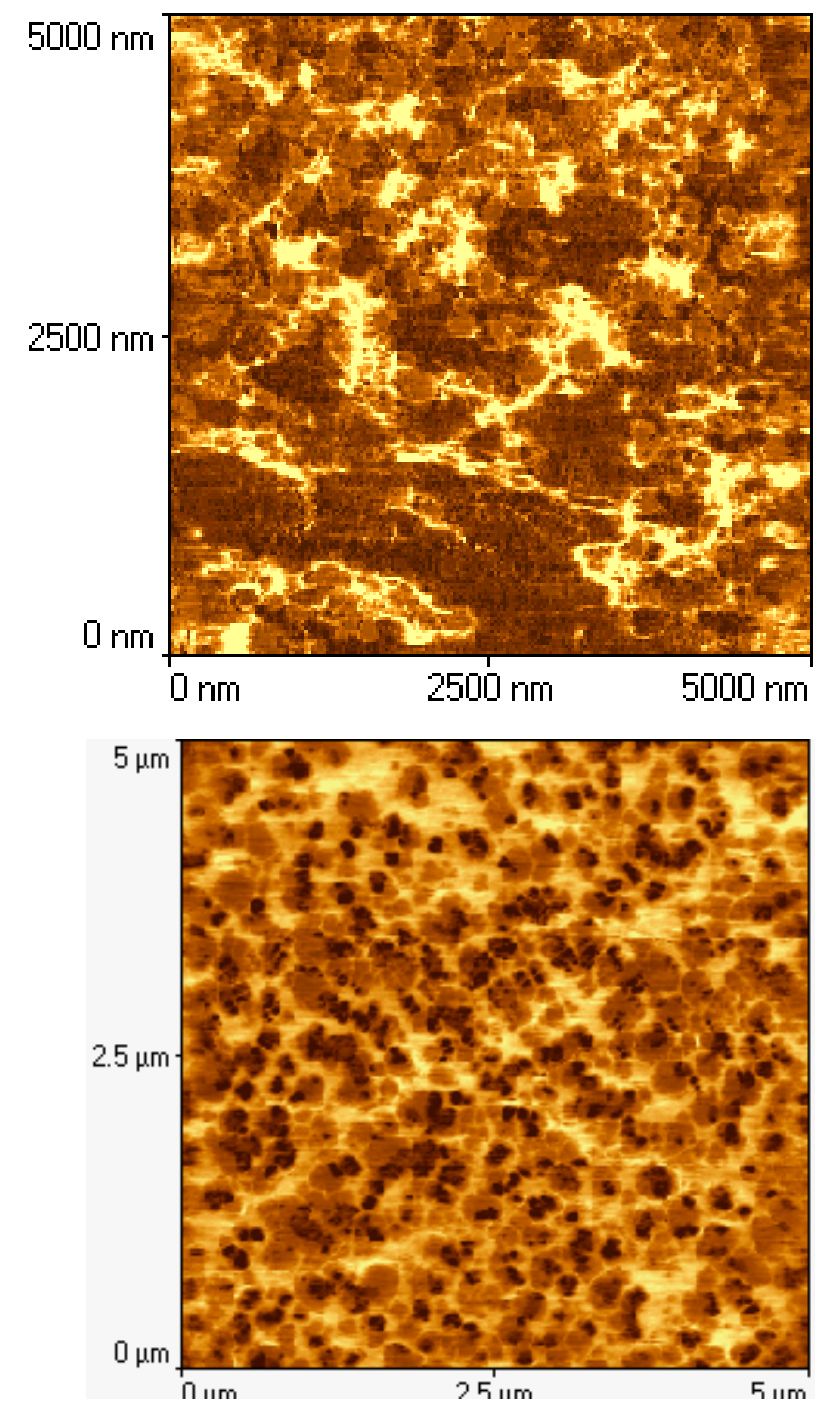

ZDDP

MoDTC

Fig 7 Topography and LF after two hours rubbing for g-DLC 


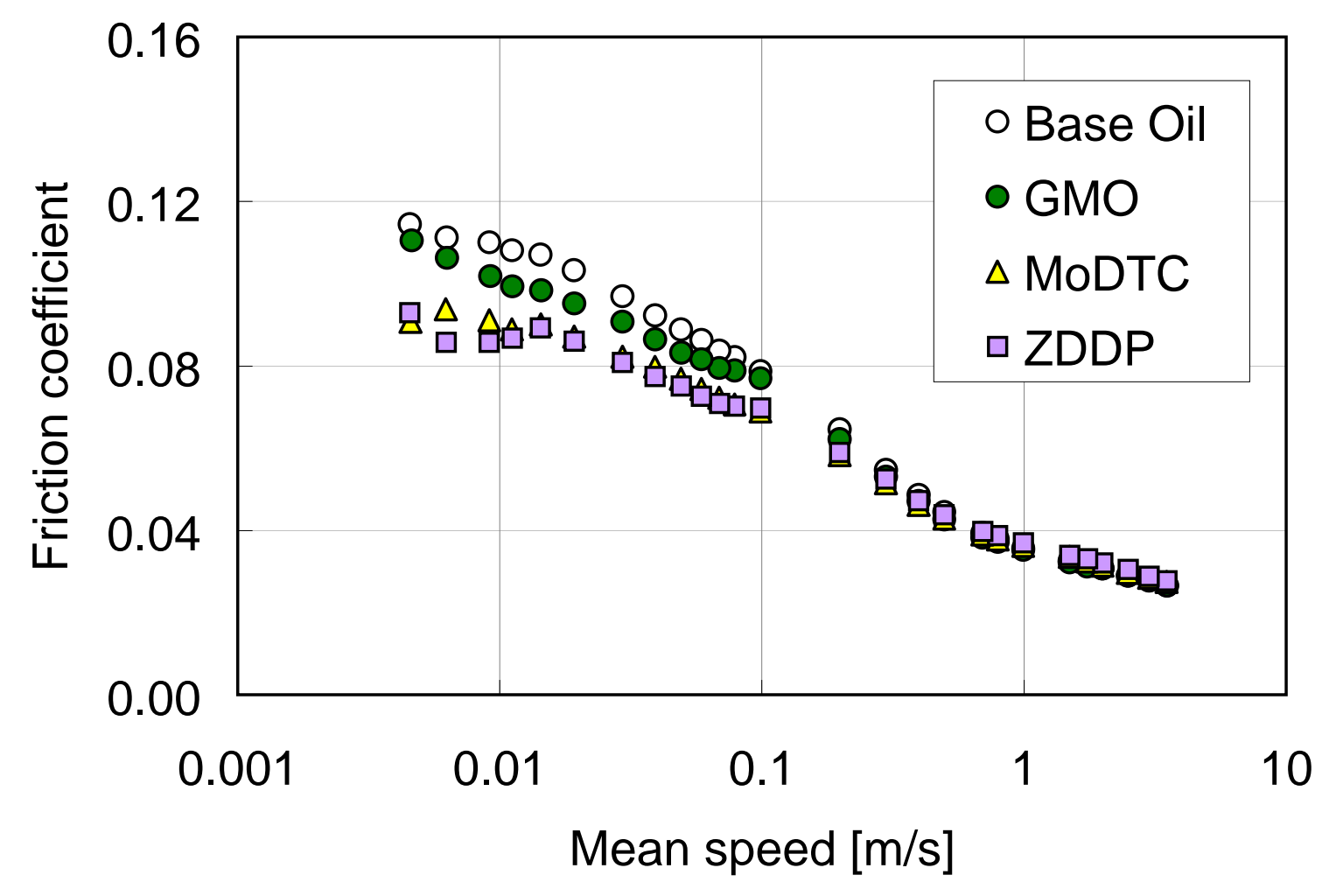

Fig. 8a Immediate effect of FMs on friction for d-DLC 


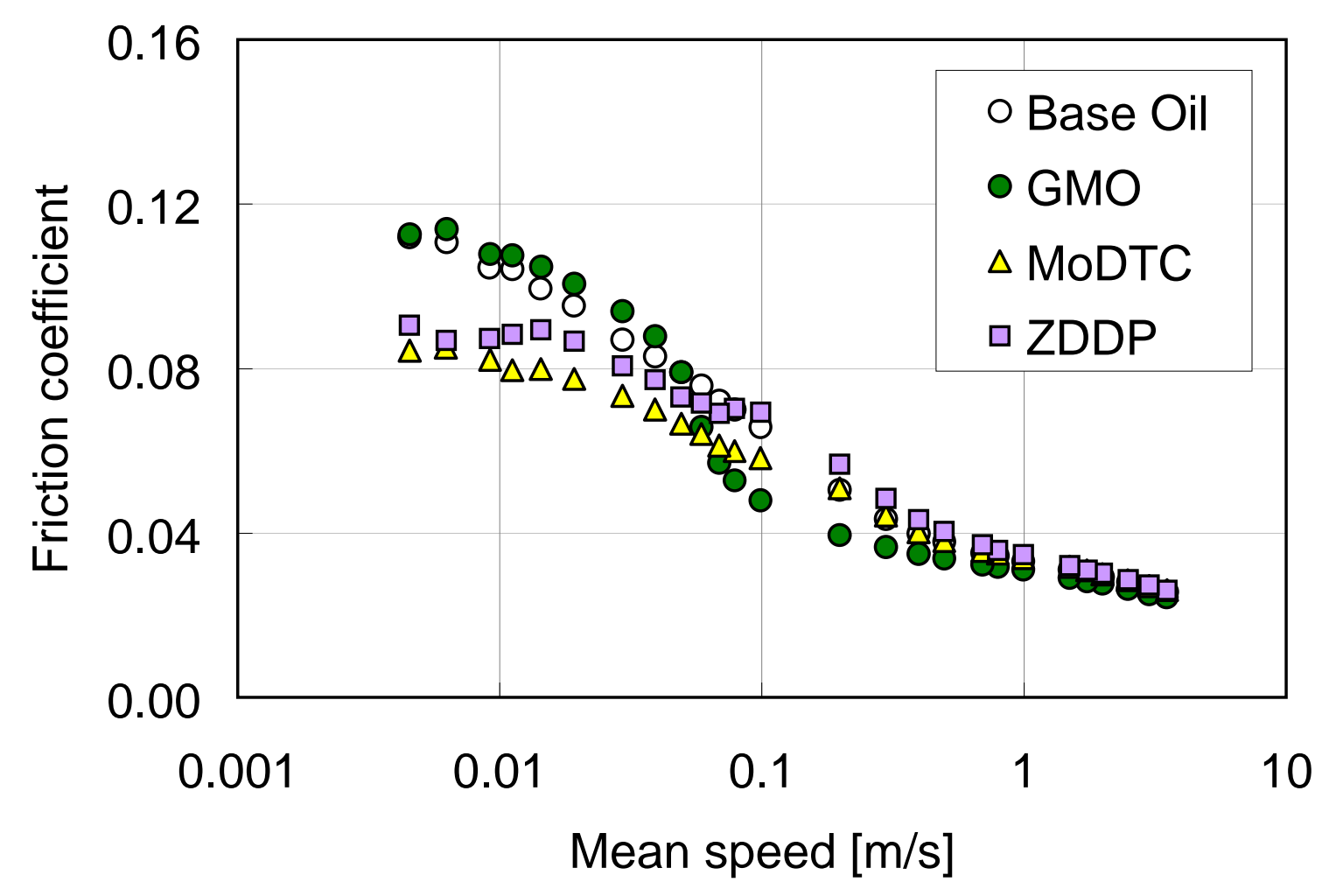

Fig. 8b Effect of FMs on friction after two hours rubbing for d-DLC 
topography
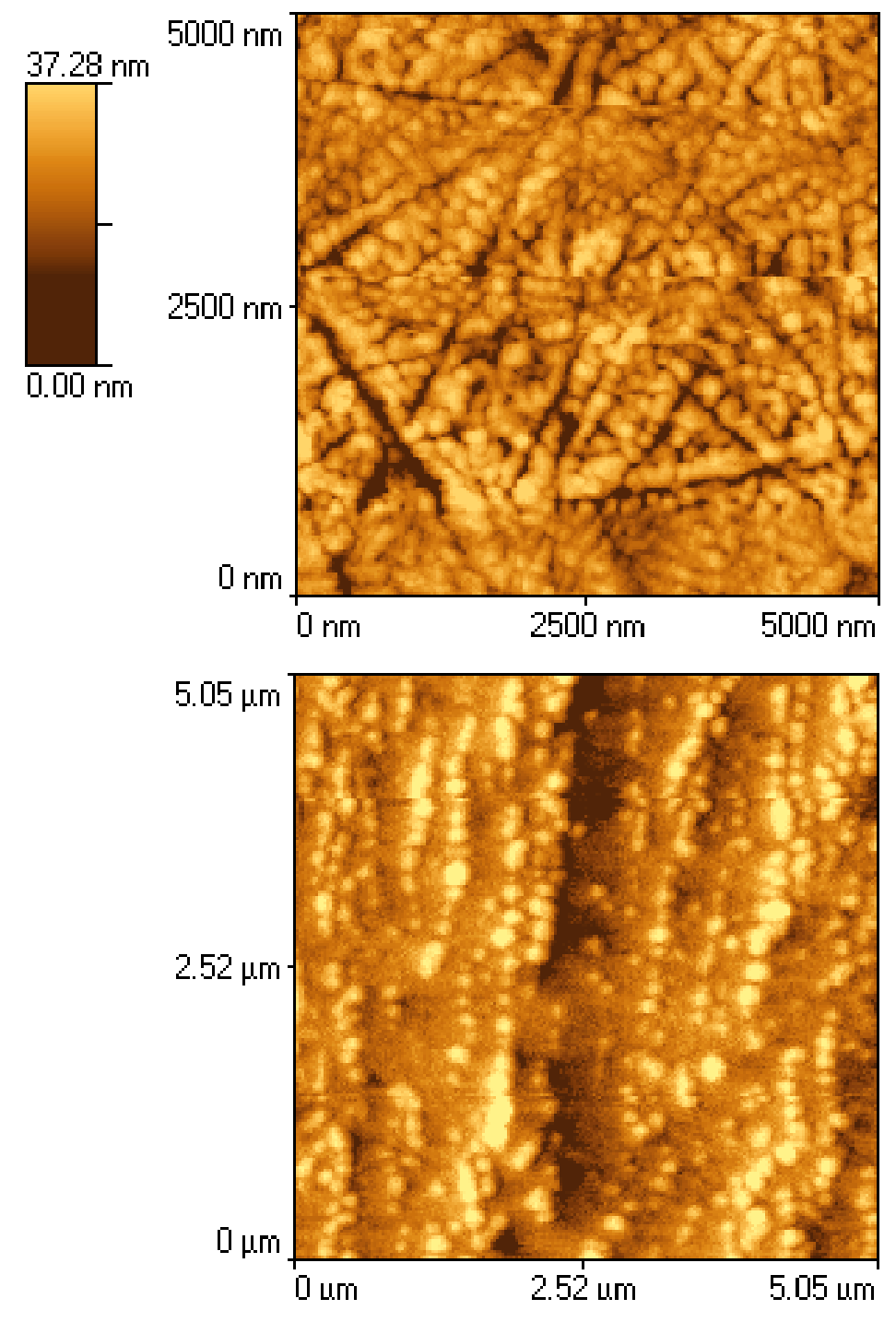

lateral force
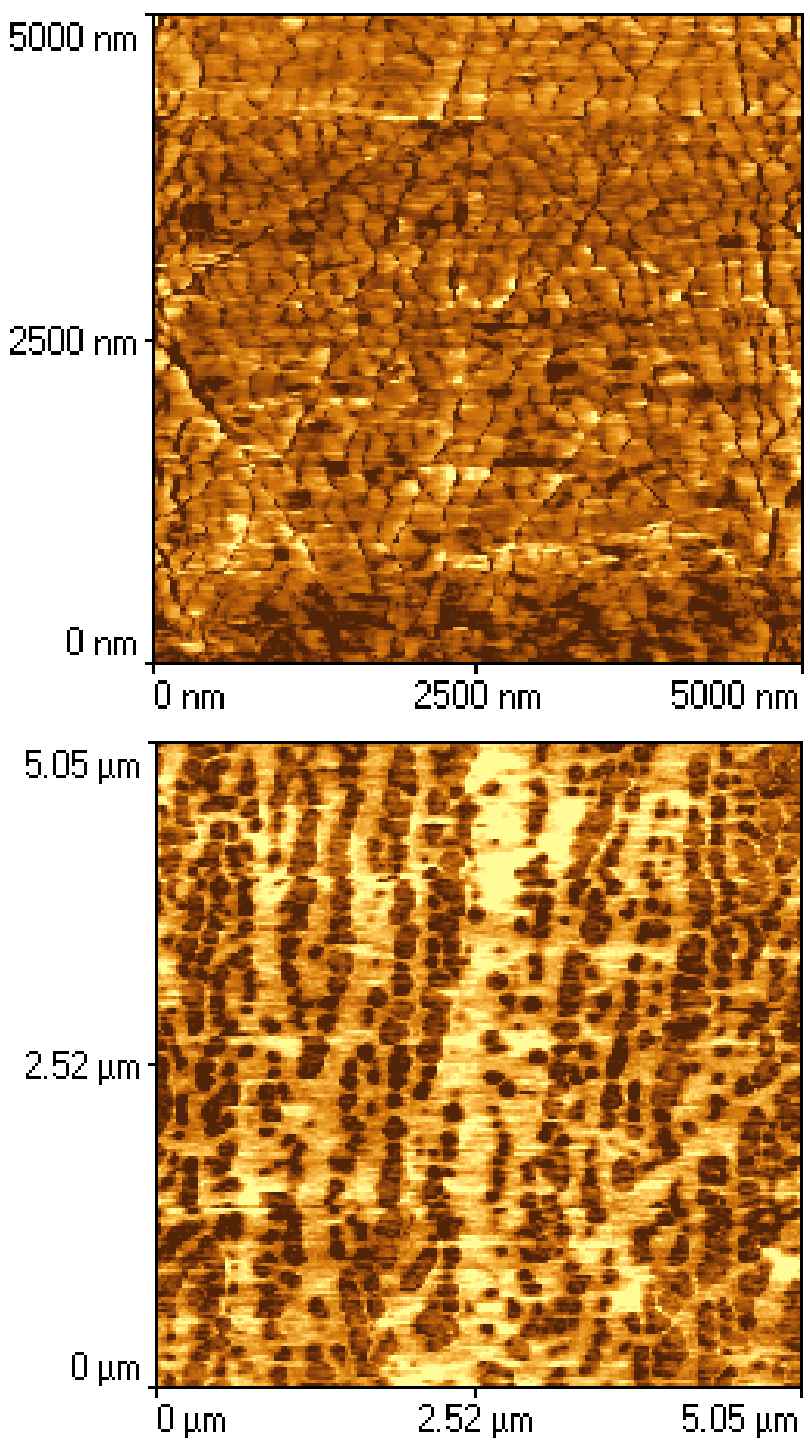

ZDDP

MoDTC

Fig 9 Topography and LF after two hours rubbing for d-DLC 

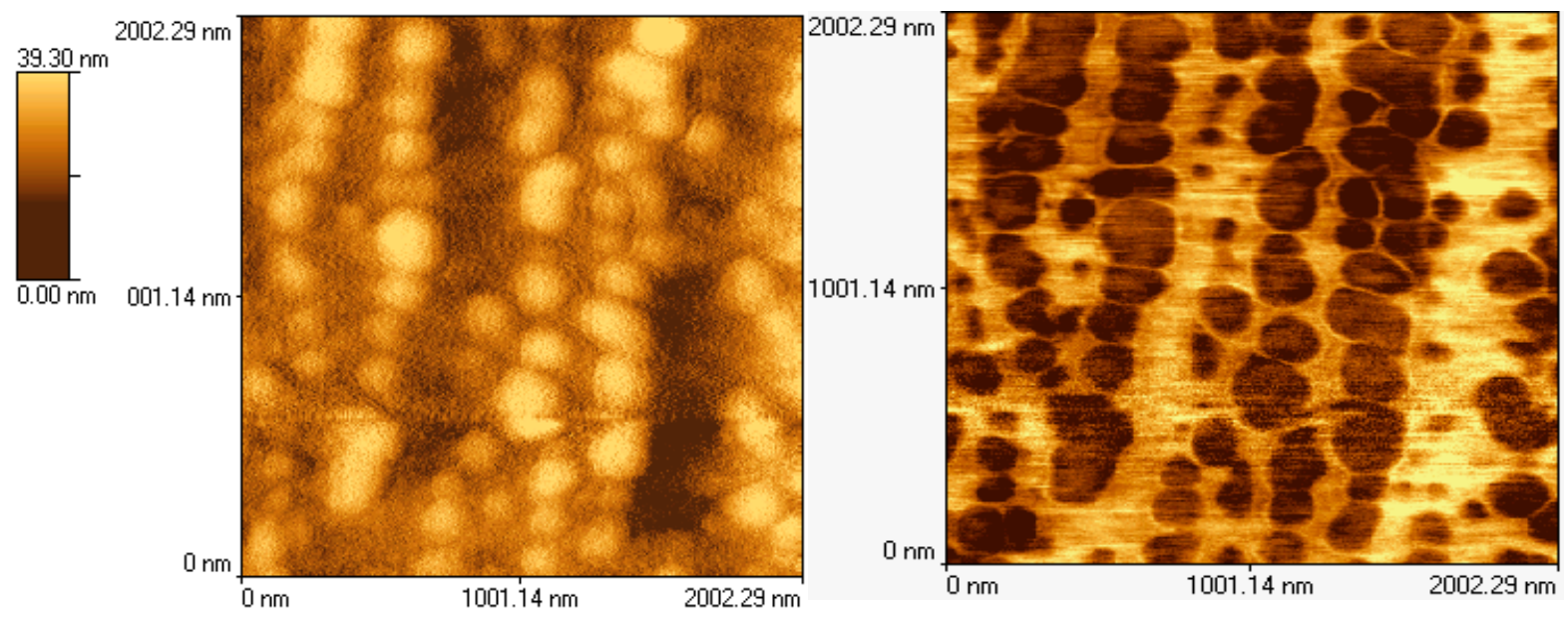

\section{d-DLC}
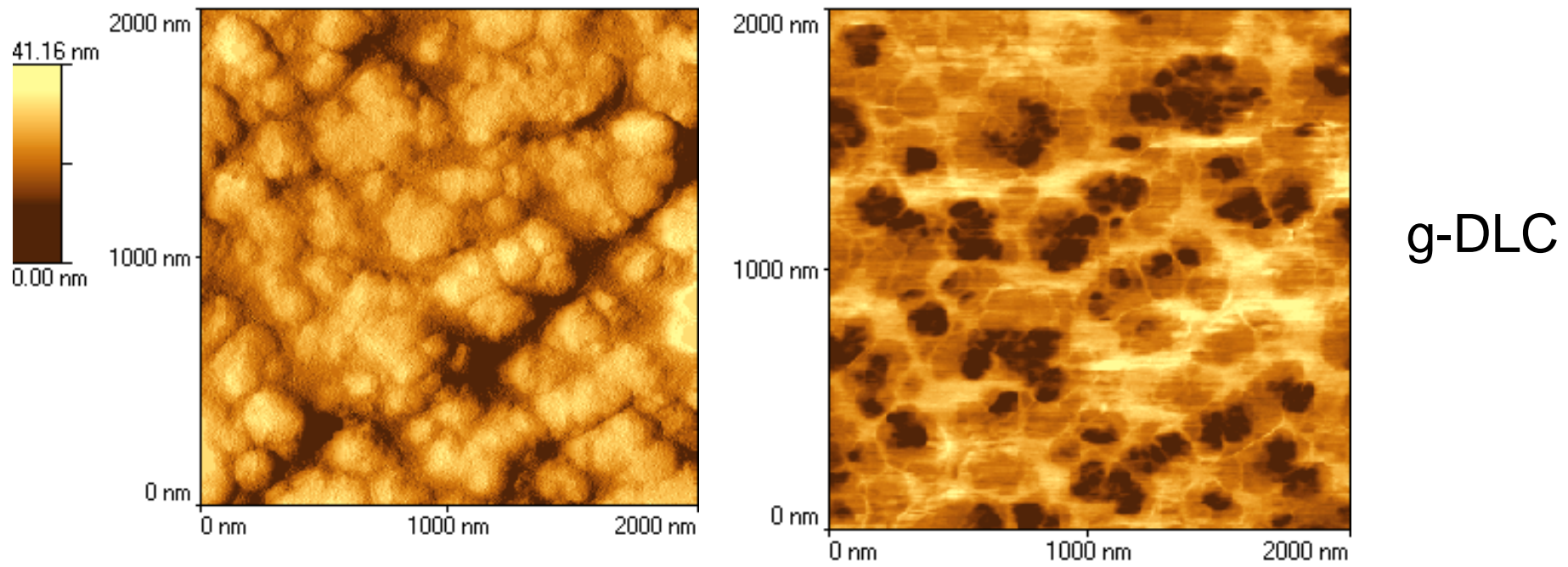

Fig 10 Topography and LF of d-DLC and g-DLC after two hours rubbing in MoDTC solution 

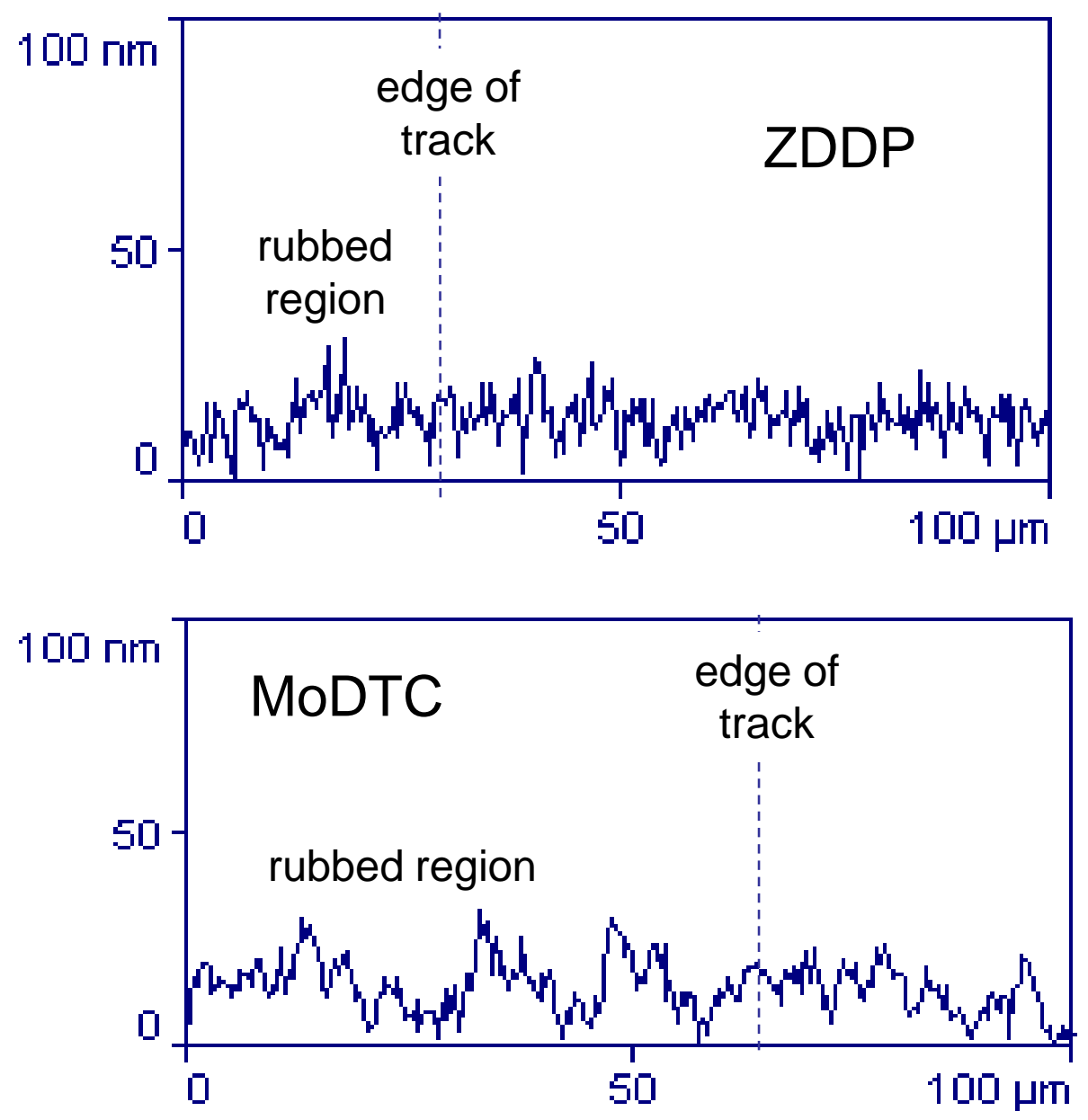

Fig 11 Profile across edge of rubbed track for d-DLC rubbed in ZDDP and MoDTC solutions 